\begin{tabular}{|c|c|c|c|c|c|c|}
\hline \multirow{4}{*}{ Impact Factor: } & ISRA (India) & $=3.117$ & SIS (USA) & $=0.912$ & ICV (Poland) & $=6.630$ \\
\hline & ISI (Dubai, UAE & $=0.829$ & РИНЦ (Russia) & $=0.156$ & PIF (India) & $=1.940$ \\
\hline & GIF (Australia) & $=0.564$ & ESJI (KZ) & $=8.716$ & IBI (India) & $=4.260$ \\
\hline & JIF & $=1.500$ & SJIF (Morocco) & $=5.667$ & OAJI (USA) & $=0.350$ \\
\hline
\end{tabular}

SOI: $1.1 /$ TAS $\quad$ DOI: $10.15863 / T A S$
International Scientific Journal
Theoretical \& Applied Science
p-ISSN: $2308-4944$ (print) $\quad$ e-ISSN: $2409-0085$ (online)
Year: $2019 \quad$ Issue: $06 \quad$ Volume: 74
Published: $10.06 .2019 \quad \underline{\text { http://T-Science.org }}$

QR - Issue

QR - Article
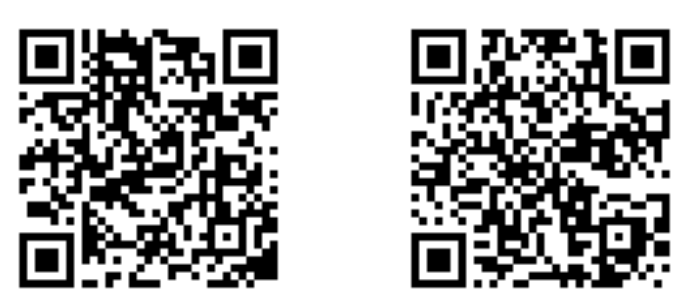

Stanislav Igorevich Bolsun

Peter the Great St. Petersburg Polytechnic University student,

iters@yandex.ru

Vadim Andreevich Kozhevnikov

Peter the Great St. Petersburg Polytechnic University

Senior Lecturer,

vadim.kozhevnikov@gmail.com

Oleg Yurievich Sabinin

Peter the Great St. Petersburg Polytechnic University

assistant professor,

olegsabinin@mail.ru

\title{
DESCRIBING LOGGING POLICY FOR IT COMPANY TO IMPROVE SYSTEM MAINTENANCE FOR COMPUTER PROGRAMMERS AND SYSTEM ADMINISTRATORS
}

Abstract: The article describes a logging policy for an IT company to improve the quality of application monitoring for developers and system administrators. It also describes the recommended improvements for the logging open source library to integrate it into the new logging policy.

Key words: logging, Kotlin, monitoring, quality of system maintenance.

Language: English

Citation: Bolsun, S. I., Kozhevnikov, V. A., \& Sabinin, O. Y. (2019). Describing logging policy for it company to improve system maintenance for computer programmers and system administrators. ISJ Theoretical \& Applied Science, 06 (74), 82-86.

Soi: $\underline{\text { http://s-o-i.org/1.1/TAS-06-74-5 Doi: crossef https://dx.doi.org/10.15863/TAS.2019.06.74.5 }}$

\section{Introduction}

Every day new products are born and requirements for IT products will certainly grow due to the growth of the market. So, computer programmers and system administrators have to monitor the system in real-time by different monitoring systems like Prometheus with Grafana and common logging files, that's can be used in ELK stack (ElasticSearch + Logstash + Kibana). Thus, it's very important to think about the structure of logging: How we should write it? In which places and how often we should logging? How to write logs which will be understood by other employees, not only programmers, who wrote this piece of code? Do we need a common logging policy to our company to maintain the quality of the system at a high level and that the logs remain homogeneous in the entire application?

Modern realities force companies to develop their logging policies, that extends to the entire product and to each developer. So, this article offers a logging policy (that was introduced in one FinTech company) for IT company and modifications for logging library ( Slf $4 \mathrm{j}$ with $\log 4 \mathrm{j}$ ) to integrate it into the mentioned earlier logging policy. $[1,2]$ system

Describing API of the improved logging

We assume the library has a LogTag class which is responsible for a separate tag (EXCEPTION, START, FINISH ...) and related information - a serial number and a description. The LogTags class wraps 


\begin{tabular}{|c|c|c|c|c|c|c|}
\hline \multirow{4}{*}{ Impact Factor: } & ISRA (India) & $=3.117$ & SIS (USA) & $=0.912$ & ICV (Poland) & $=6.630$ \\
\hline & ISI (Dubai, UAI & $=0.829$ & РИНЦ (Russia & $=0.156$ & PIF (India) & $=1.940$ \\
\hline & GIF (Australia) & $=0.564$ & ESJI (KZ) & $=8.716$ & IBI (India) & $=4.260$ \\
\hline & JIF & $=1.500$ & SJIF (Morocce & $=5.667$ & OAJI (USA) & $=0.350$ \\
\hline
\end{tabular}

the LogTag and stores all the listed tags (LogTag) for a particular entry. LogTags operates with methods to add new tags, remove tags from the set, intersect tags and provide tags toString() representation as an ordered and formatted string.

The LogTiming class proposed to be responsible for storing the operation duration time in milliseconds inside a variable type of Long. This class not only stores the duration of the operation but also provides a method for forming a textual representation of the current object.

The LogTuple class is a common tuple which stores a single key and its associated value. The LogTuples class is a wrapper for LogTuple, that is, it stores a set of tuples. The methods of the LogTuples class allow you to operate on tuples - add a new tuple, form a set of tuples from the Mapped Diagnostic Context - provide a textual representation of a set of tuples for a logging entry. [3]

The LogMessage class is a representation of the complete log entry, which contains LogTiming,
LogTags, LogTuples, the cause exception and, accordingly, the text message itself with the necessary parameters. It is this class that forms the complete line for passing it to $\log 4 \mathrm{j}$ for further processing.

The Log class is the util class for quickly creating a LogMessage object with a single tag value, timing, tuple, exception, or message.

In the new logging policy, all logging operations are performed through the logger package ru.payment.system.logging.base. It applies the delegation pattern to the standard $\log 4 \mathrm{j}$ logger, but takes as its parameters a new object of the LogMessage class, described earlier. [4]

\section{Describing the logging policy key feature}

The first feature requires logging all exit points from the method with messages, that describes a business task that was completed before method completion (see Figure 1).

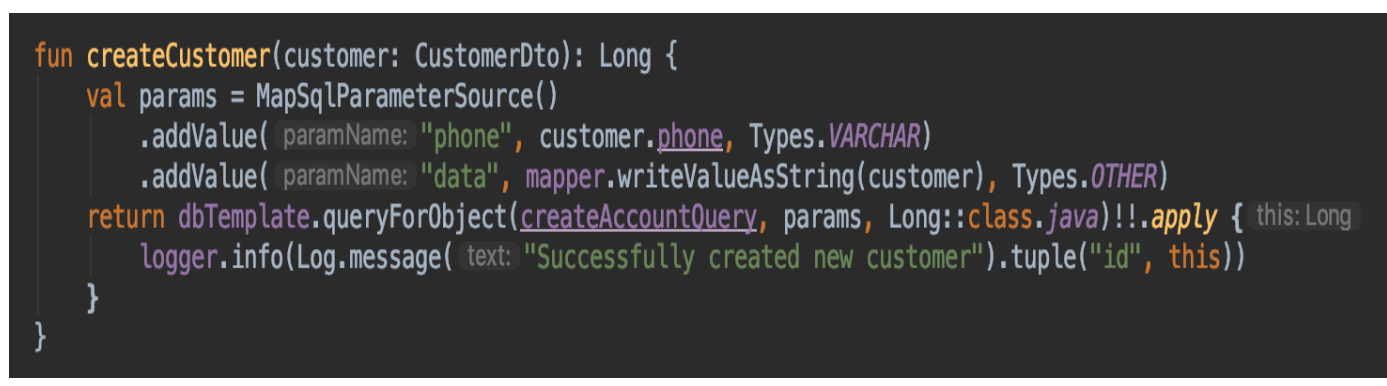

Figure 1 - first feature of logging policy

The second feature requires logging all GET HTTP requests with logging all URL parameters in the first line of the controller method, that receives a request. It information needs to state a fact of receiving an incoming request with correct parameters (see Figure 2).

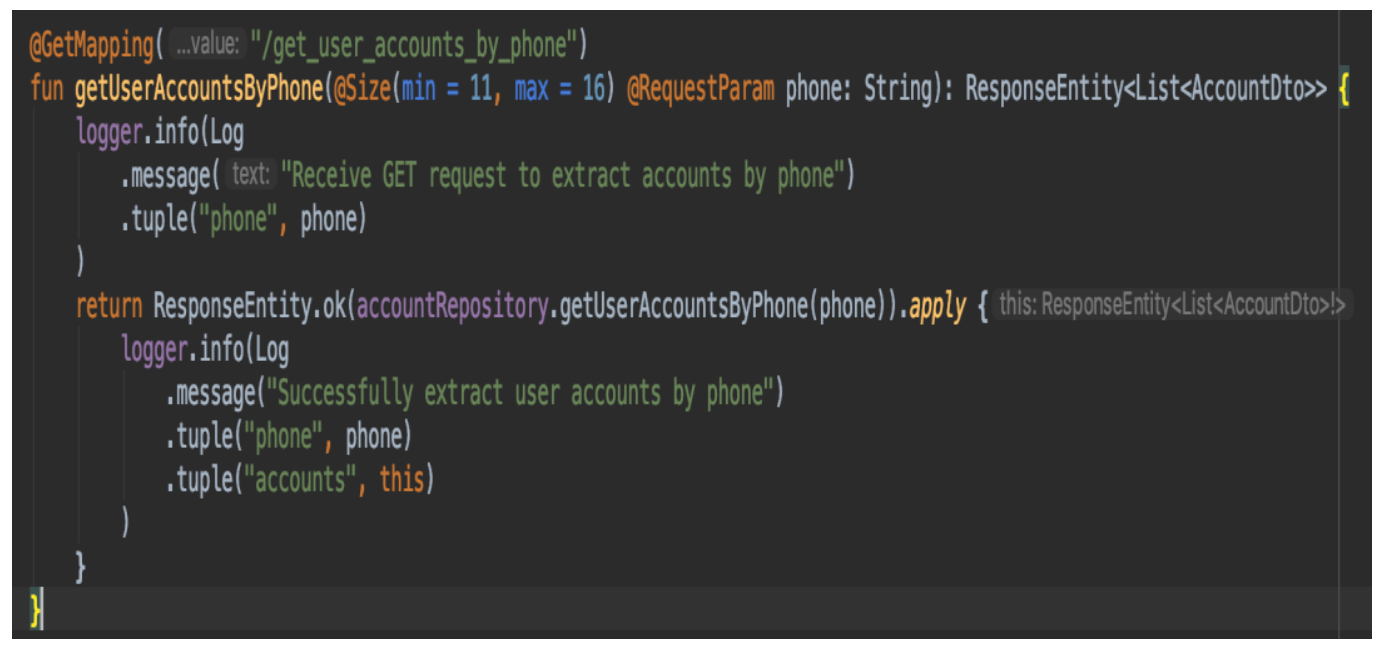

Figure 2 - second feature of logging policy 


\begin{tabular}{|c|c|c|c|c|c|c|}
\hline \multirow{4}{*}{ Impact Factor: } & ISRA (India) & $=3.117$ & SIS (USA) & $=0.912$ & ICV (Poland) & $=6.630$ \\
\hline & ISI (Dubai, UAI & $=0.829$ & РИНЦ (Russia & $=0.156$ & PIF (India) & $=1.940$ \\
\hline & GIF (Australia) & $=0.564$ & ESJI (KZ) & $=8.716$ & IBI (India) & $=4.260$ \\
\hline & JIF & $=1.500$ & SJIF (Morocce & $=5.667$ & OAJI (USA) & $=0.350$ \\
\hline
\end{tabular}

The third feature requires logging full POST HTTP request encoded body if that request is responsible for creating a new entity in the system. So in log files developers and system administrators will able to monitor of creating new entities with predefined fields (properties) (see Figure 3) [5].

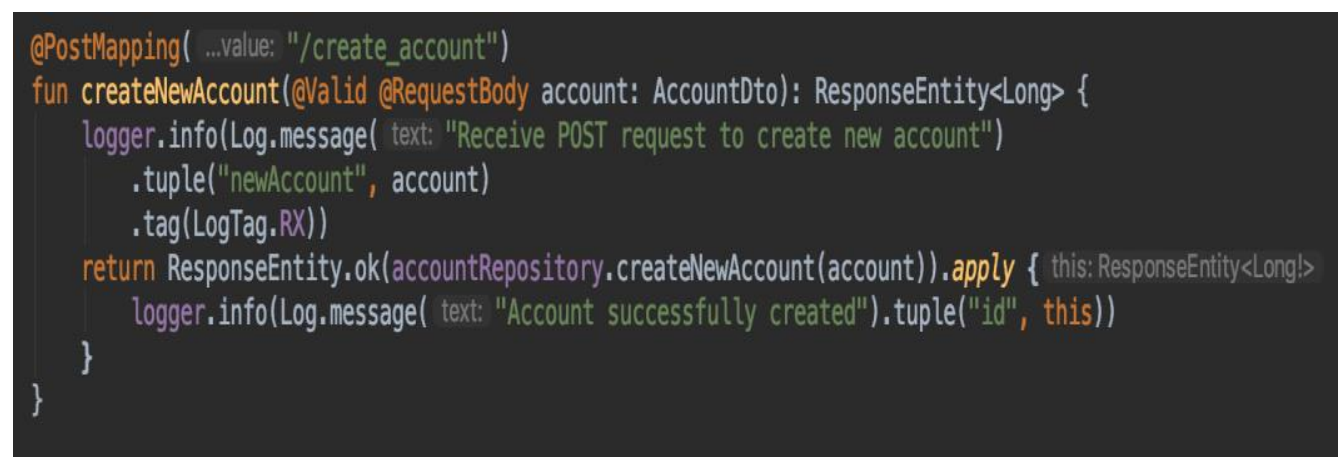

Figure 3 - third feature of logging policy

The four feature requires logging full POST HTTP request encoded body with existing entity fields (what was and what will be), if that request is responsible for updating exists entity in the application (see Figure 4).

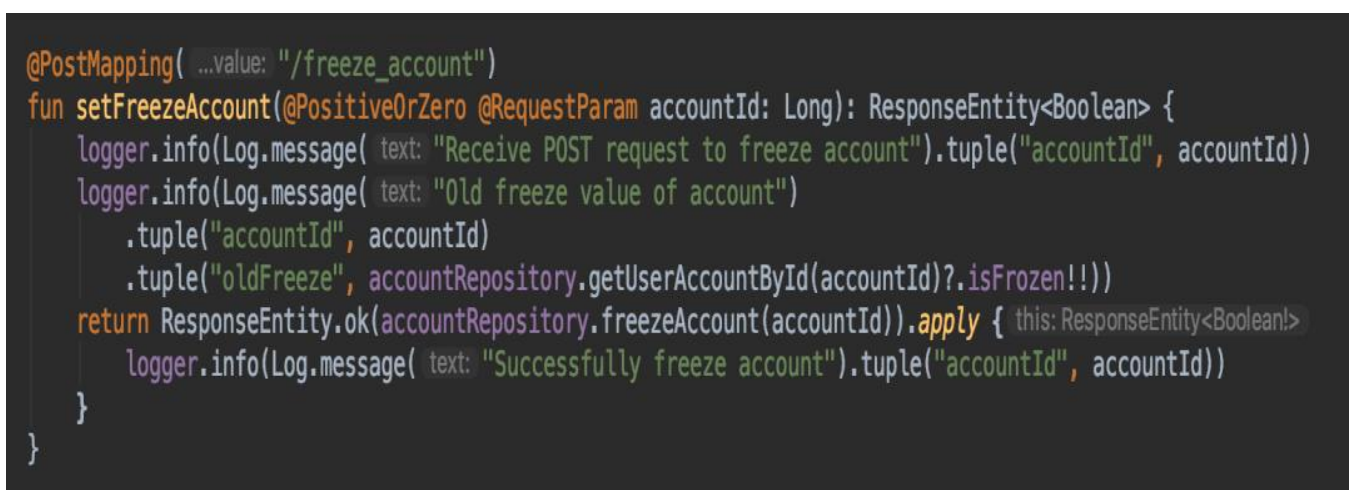

Figure 4 - four feature of logging policy

The fifth feature requires logging all outgoing requests with tag - TX, so it will speed up the search by tag if computer programmers or system administrator want to see outgoing requests in detail.
In demo payment service there is no outgoing requests.

The six feature requires logging all incoming requests with tag - $\mathrm{Rx}$, with the same meaning as in fifth feature description (see Figure 5).

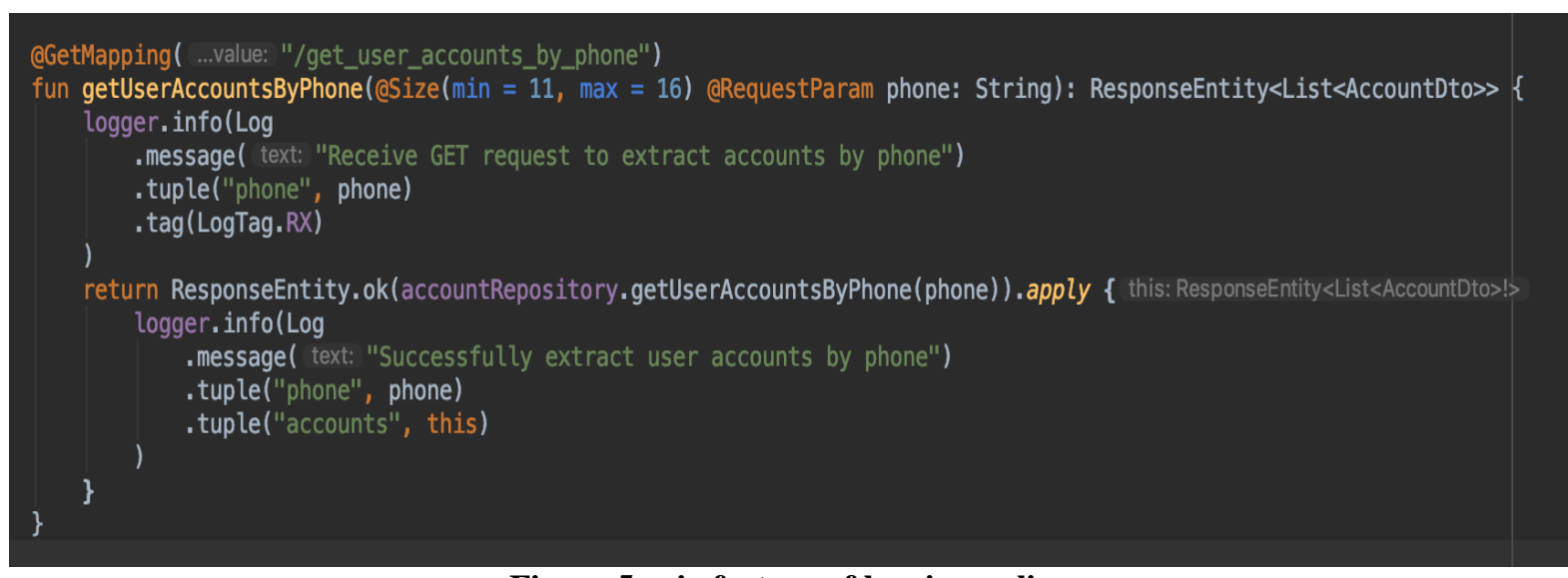

Figure 5 - six feature of logging policy 


\begin{tabular}{llllll} 
& ISRA (India) $=\mathbf{3 . 1 1 7}$ & SIS (USA) $=\mathbf{0 . 9 1 2}$ & ICV (Poland) & $\mathbf{= 6 . 6 3 0}$ \\
Impact Factor: & ISI (Dubai, UAE) $=\mathbf{0 . 8 2 9}$ & PUHЦ (Russia) $=\mathbf{0 . 1 5 6}$ & PIF (India) & $=\mathbf{1 . 9 4 0}$ \\
& GIF (Australia) $=\mathbf{0 . 5 6 4}$ & ESJI (KZ) & $\mathbf{8 . 7 1 6}$ & IBI (India) & $=\mathbf{4 . 2 6 0}$ \\
& JIF & $\mathbf{1 . 5 0 0}$ & SJIF (Morocco) $=\mathbf{5 . 6 6 7}$ & OAJI (USA) & $\mathbf{0 . 3 5 0}$ \\
\hline
\end{tabular}

The seventh feature requires logging all exception cases with tag - EXCEPTION to monitor extraordinary cases by special useful tag. This tag very

important for system administrators while the deploying microservice on production to decide if need rollback for this release (see Figure 6).

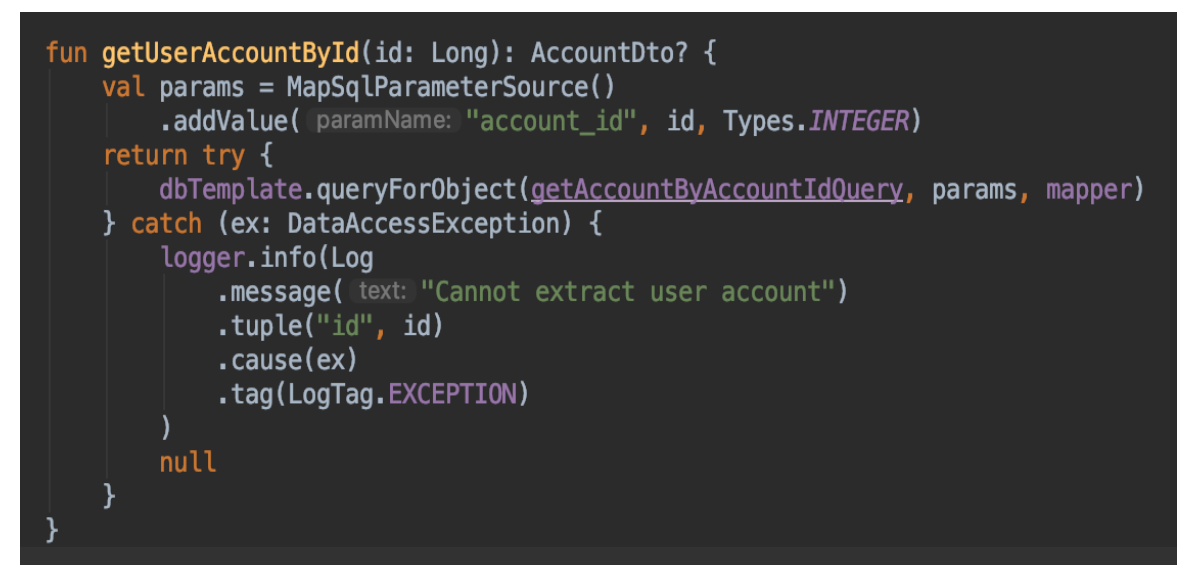

Figure 6 - seventh feature of logging policy

\section{Advantages of the new approach}

With the introduction of the logger and the new policy into operation, the following advantages can be distinguished compared to the usual logger Slf4j and informal logging:

1) there is a convenient opportunity to quickly search for tags using Linux utilities grep and less; [6]

2) there is an understandable plan for logging and clear requirements for log entries, so the trace becomes homogeneous and structured;

3) the obligatory condition of additional parsing of log entries in CSV format (using the strategy developed when modifying the logger) allows you to build analytical repositories that can easily parse and use incoming format (CSV); [7]

4) system behavior has become easier and more convenient to monitor - each team member knows which log file to look at and what information can be obtained from it;

5) due to a clear plan and requirements for logs, unnecessary (unnecessary, irrelevant) logs became less. Thus, disk space is spent more efficiently;

6) due to the clear structure of the logs and the CSV format, the possibility of abandoning monitoring systems, such as Prometheus and Grafana, has appeared. Logs can be parsed in real time and display graphics on the screen; [8, 9]

7) It has become easier for system administrators to maintain working components - the fact of an error is important for them, and not the stack trace (which usually has large sizes and does not fit in one terminal session), which carries an informative load only for developers;

\section{Disadvantages of the new approach}

When introducing a new logging policy and a modified logger, several weaknesses were also identified:

1) a new dependency must be added to the project with a modified logger;

2) the need to bring a new logging API for each developer in the team;

3) teams need a tougher and more attentive review code to keep the logging system in a homogeneous state;

4) The "old" Slf4j API is still available for developers and they can use it by mistake;

All these drawbacks lose their significance against the background of the advantages that we get for monitoring the whole application (microservice) within a large team of developers and system administrators whose work and time are expensive. [10]

\section{Conclusion}




\begin{tabular}{llllll} 
& ISRA (India) $=\mathbf{3 . 1 1 7}$ & SIS (USA) $=\mathbf{0 . 9 1 2}$ & ICV (Poland) & $\mathbf{= 6 . 6 3 0}$ \\
Impact Factor: & ISI (Dubai, UAE) $=\mathbf{0 . 8 2 9}$ & PUHЦ (Russia) $=\mathbf{0 . 1 5 6}$ & PIF (India) & $=\mathbf{1 . 9 4 0}$ \\
& GIF (Australia) $=\mathbf{0 . 5 6 4}$ & ESJI (KZ) & $\mathbf{8 . 7 1 6}$ & IBI (India) & $=\mathbf{4 . 2 6 0}$ \\
& JIF & $\mathbf{1 . 5 0 0}$ & SJIF (Morocco) $=\mathbf{5 . 6 6 7}$ & OAJI (USA) & $\mathbf{0 . 3 5 0}$ \\
\hline
\end{tabular}

When introducing and operating a new logging policy and a modified library, the quality of monitoring components inside the system was significantly improved, the work of system administrators (who do not know the business code and the tasks performed inside the components as thoroughly as the developers know) was greatly facilitated. Due to a large amount of work on implementation and maintenance, first, the new approach will be extended to new components that are not yet in production, as well as to the most key places of the legacy system (which perform key tasks in the payment system). Over time, an increasing number of components and modules will apply a new approach to logging, which has proven successful for industrial development.

\section{References:}

1. (n.d.). SLF4J documentation. Retrieved June 02, 2019, from https://www.slf4j.org/docs.html

2. (n.d.). $\log 4 \mathrm{~J}$ documentation. Retrieved June 03, 2019 , from https://logging.apache.org/log4j/2.x/javadoc.ht $\underline{\mathrm{ml}}$

3. (n.d.). $\log 4 \mathrm{j}-\log 4 \mathrm{j} 2$ Thread Context. Retrieved June 03, 2019, from https://www.baeldung.com/mdc-in- $\log 4 \mathrm{j}-2-$ logback

4. (n.d.). Delegation pattern. Retrieved June 03, 2019, from https://en.wikipedia.org/wiki/Delegation_patter $\underline{\mathrm{n}}$

5. (n.d.). In Introduction to HTTP Basics. Retrieved June 03, 2019, from https://www.ntu.edu.sg/home/ehchua/program ming/webprogramming/HTTP_Basics.html
6. (n.d.). Using less and grep with logs. Retrieved June $\quad 04, \quad 2019, \quad$ from https://www.ianlewis.org/en/using-less-andgrep-with-logs

7. (n.d.). Comma-separated values format. Retrieved June 04, 2019, from https://en.wikipedia.org/wiki/Commaseparated values

8. (n.d.). Prometheus documentation. Retrieved June 05, 2019, from https://prometheus.io/docs/introduction/overvie w/

9. (n.d.). Grafana documentation. Retrieved June 05, 2019, from https://grafana.com/docs/

10. (n.d.). Microservice. Retrieved June 05, 2019, from

https://en.wikipedia.org/wiki/Microservices 